\title{
A variação linguística do português moçambicano: uma análise sociolinguística da variedade em uso
}

\author{
Alexandre António Timbane \\ Academia de Ciências Policiais - Moçambique \\ Universidade Federal de Goiás- Brasil
}

\section{Introdução}

O estudo da língua em seu contexto social tem merecido espaço privilegiado por parte de linguistas com maior ênfase, a partir dos anos 1960, com os trabalhos do linguista americano William Labov. A língua tem uma função social - o da comunicação - e ela só pode ser compreendida e interpretada dentro do contexto sociocultural. É importante compreender que a língua não é um sistema uno, invariado, estático, mas, necessariamente, abriga um conjunto de variedades, variantes e dialetos. Todas as línguas são moldadas pelos contextos socioculturais e a sua variação e mudança dependem da forma como os usuários replicam o seu uso.

Em Moçambique, não é exceção. Todas as línguas faladas tendem a mudar com o tempo desviando-se constantemente com relação à norma. Sendo assim, a norma não é apenas ou simplesmente um conjunto de formas linguísticas pré-estabelecidas, mas, também, é um agregado de valores socioculturais usados por uma comunidade linguística. Acerca mais especificamente do contexto moçambicano, observa-se que a escola apoia-se no português de Portugal (norma-padrão europeia) para ensinar e avaliar competências em português dos alunos, o que faz com que os alunos não progridam academicamente. É importante deixar claro que a variação não é exclusiva dos falantes não-escolarizados. Ninguém fala 'norma-padrão' a todo momento, pois ela é artificial, ou seja, não é língua materna de ninguém.

Algumas entidades moçambicanas não entendem que se trata do momento certo para discutir a variedade do Português de Moçambique (PM) por ser cedo demais! A presente pesquisa ruma contrária a essa ideia, demonstrando que a variação do português em Moçambique nunca avisará a sua chegada. Baseando-se na fala cotidiana dos moçambicanos, é possível perceber que o português europeu não está presente em Moçambique. Até porque vários estudos (como de Cintra, 
1971, por exemplo) mostram que, em Portugal, não se fala português da mesma forma em todas as províncias e vilarejos. Ou ainda, estudos mostram a existência de dialetos distribuídos de forma desigual naquele país (Cintra, 1971). Em Moçambique, não há dialetos, mas uma variedade do português que se distancia do português europeu linguisticamente falando. É necessário evidenciar, portanto, que o português falado/escrito em Moçambique difere-se do que é escrito/falado em outros países da lusofonia.

O objetivo desta pesquisa é de explicar as condições sócio-históricas que comparticiparam na formação do PM. Assim, ao se considerar que o PM é uma variedade que resulta de contextos sociolinguísticos e da diversidade cultural, questiona-se: como surgiu o PM e quais as suas características? Dessa forma, a pesquisa tem por objetivo discutir a situação do PM tendo em conta as variáveis sociais; explicar as características léxico-semânticas e sintáticas. Nesse sentido, a pesquisa é relevante porque desperta a necessidade de afirmação própria da variedade moçambicana, bem como da redução do preconceito linguístico que aflige o sistema educativo do país.

Inicialmente (seção 1), discute-se como apareceu o português em Moçambique e qual a política linguística colonial que comparticipou na formação da variedade moçambicana, assim como a influência das Línguas Bantu moçambicanas (doravante, LBm). Mais adiante (seção 2), discute-se a relação entre a transmissão linguística irregular e a formação do PM. Nesse ponto, faz-se uma correlação com a formação dos crioulos. Na seção 3, por sua vez, apresentam-se os conceitos de PM e dos moçambicanismos e sua relação com a formação de uma variedade. Na seção 4, apresenta-se o material de pesquisa e discutem-se os seus resultados, sempre procurando mostrar que o PM é uma realidade presente e cabe a cada linguista contribuir para a sua descrição bem como para a criação de gramáticas e de dicionários que refletem esta realidade moçambicana.

\section{Situação linguística de Moçambique antes e depois da colonização}

Moçambique é um país africano, localizado na África Austral, que tem pouco mais de vinte milhões de habitantes, socioculturalmente divididos em várias etnias, cada uma delas caracterizada por uma diversidade linguística extensa. Não é conveniente, nesse contexto, discutir a situação linguística de Moçambique sem fazer alusão à situação linguística em nível continental. Sendo assim, África possui quatro grandes famílias de línguas: (a) Níger-congo formado por 1,436 línguas; (b) afroasiático com 371 línguas; (c) Nilo-sahariano com 196 línguas e (d) khoisan com cerca de 35 línguas (Heine; Nurse, 2000). 
É dentro da família Níger-congo em que se encontram as línguas bantu, que constituem um grupo de línguas localizadas geograficamente na África Ocidental, Central e se estende até a região Austral do continente com características linguísticas comuns. Usando o método comparativo, o linguista Guthrie (1948) percebeu que as semelhanças consistiam em: (a) o uso extensivo de prefixos; (b) cada substantivo pertence a uma classe; (c) cada idioma pode ter dez ou mais classes; (d) a classe é indicada por um prefixo no substantivo, como também em adjetivos e verbos que concordam com aquele; e (e) o plural é indicado por uma mudança de prefixo.

Sendo assim, em Moçambique, fala-se kimwani, shimaconde, ciyawo, emakhuwa, echuabu, cinyanja, cinyungwe, cisena, cibalke, cimanyika, cindau, ciwute, gitonga, citshwa, cicopi, xichangana, xirhonga (Ngunga, Faquir, 2011) e outras línguas cuja padronização ortográfica não foi realizada, mas que são faladas por grupos populacionais espalhados pelo país e localizados geograficamente em regiões rurais e isoladas. Existem línguas fronteiriças faladas em Moçambique e em países vizinhos tais como o nindi (da Tanzânia), o nsenga (da Zâmbia), o shona e o kunda (do Zimbábue) e outras citadas por Timbane (2013b). Em Moçambique, também se falam algumas línguas de origem asiática vindas com emigrantes e povos que se instalaram nas principais capitais de Moçambique e desenvolveram atividades comerciais. São elas: língua gujarati, língua memane, língua hindu, língua urdo e língua árabe (Timbane, 2014).

As línguas estrangeiras modernas (inglês e francês) também são faladas no território motivadas pelo fenômeno da globalização em que Moçambique se encontra envolvido. O país faz fronteira com seis países anglófonos e, por isso, é interessante conhecer a língua do "vizinho" para melhor estabelecer relações de amizade e de solidariedade. A maioria destas LBm são internacionais, quer dizer, são faladas também em vários países africanos. Podem-se citar exemplos de swahili que, para além de ser falado em Moçambique, é falado por cerca de 50 milhões pessoas localizadas geograficamente no Quênia, Tanzânia, Uganda, Republica Democrática do Congo, Ruanda, Burundi, Somália Zâmbia, Partes de Madagascar e Comores, segundo Moshi (2006). Isso significa que as fronteiras linguísticas são diferentes das fronteiras políticas. Para além das línguas aqui citadas, acrescenta-se a língua de sinais que poucas vezes tem sido referenciada em pesquisas sobre as línguas de Moçambique. Mais especificamente sobre essa língua de sinais moçambicana, nota-se a existência de poucas pesquisas até o momento e o fato de o primeiro dicionário só ter sido publicado em 2013, pelo professor e pesquisador Armindo Ngunga, docente da Universidade Eduardo Mondlane. 
A presença da LP em Moçambique e em todos os Países Africanos de língua Oficial Portuguesa (PALOP) está intimamente ligada à colonização. O primeiro colonizador português Vasco da Gama chegou à Moçambique em 1497 e a primeira povoação portuguesa se fundou em 1530, na região de Sena (região central de Moçambique). É importante sublinhar que antes da chegada dos portugueses, os árabes já estabeleciam relações comerciais com africanos, em particular com os moçambicanos da região norte, divulgando também a sua religião, o islã, bem como a língua árabe utilizada de forma obrigatória na prática da fé.

Sendo assim, a ocupação efetiva de Moçambique e a implementação do sistema colonial foi possível em 1885, aquando da Conferência de Berlim (Partilha de África). Neste período, a "Igreja Católica e o empreendimento colonial estiveram estreitamente vinculados, física e ideologicamente, desde os primórdios da expansão portuguesa e, à vista dos colonizadores, confundiam-se num único objetivo" (Zamparoni, 1998, p.416). Os colonizadores portugueses utilizavam a língua como meio de dominação, pois excluíam assim as línguas africanas em todas as esferas do poder estabelecendo mitos que classificavam as LB como "incapazes de cumprir certas funções, sobretudo a de veicular as noções modernas, os conceitos abstratos e científicos, invariáveis com línguas de ensino, de cultura ou de pesquisa" (Zamparoni, 2009, p.32).

As LB faladas em Moçambique e em Angola eram chamadas preconceituosamente por pretoguês, língua do cão, landim, dialeto, língua dos pretos, etc. "Todo dialeto é uma língua, mas toda língua não é um dialeto" (Haugen, 2001, p.100). Essa atitude preconceituosa valorizou a LP e cada vez mais se consolidava o mito que defendia que "quem falasse português era civilizado ou assimilado", ou seja, todo africano que (a) tivesse abandonado inteiramente os usos e costumes daquela raça; (b) que falasse, lesse e escrevesse em língua portuguesa; (c) que adotasse a monogamia; (d) que exercesse profissão, arte ou ofício compatíveis com a civilização europeia. Como o Estado Português não tinha capacidade nem efetivo suficiente para controlar a colônia, delegou as missões católicas e suíças para sensibilizar aos moçambicanos de modo que se tornassem pacíficos com relação ao sistema. Todas as línguas africanas eram consideradas dialetos ${ }^{1}$ pela ideologia colonial, termo preconceituoso porque todas as línguas africanas têm as mesmas competências que outra língua qualquer, quer dizer, têm uma gramática, um léxico, uma morfologia, uma sintaxe próprias. Segundo Bagno

1. Eram também chamadas ladim, língua dos pretos, língua do cão e eram proibidas principalmente nas cidades ou nas instituições públicas coloniais (Zamparoni, 1998; 2002; 2009). 
o emprego do termo dialeto, fora dos estudos científicos, sempre tem sido carregado de preconceito racial e/ou cultural. Nesse emprego, dialeto é uma forma errada, feia, ruim, pobre ou atrasada de se falar uma língua. Também é uma maneira de distinguir as línguas dos povos civilizados, brancos, das formas supostamente primitivas de falar dos povos selvagens. Essa separação é tão poderosa que se enraizou no inconsciente da maioria das pessoas. Inclusive das que declararam fazer um trabalho politicamente correto (Bagno, 2011, p.380, grifos nosso).

Essa ideologia puramente colonial se enraizou em África e em todos os países que sofreram a colonização. Na citação acima, grifamos alguns adjetivos que eram/são atribuídos às línguas africanas: erradas, feia, ruim, pobre, atrasada, etc. Conforme Bagno (2011), essa ideologia consistia em menosprezar as línguas do colonizado em prol das línguas da metrópole. O sistema colonial dificultava a vida dos moçambicanos de tal forma que só os filhos dos poucos assimilados é que tinham acesso à educação formal. Na zona rural, predominavam as LB e na zona urbana falava-se uma LP cheia de adaptações (estrangeirismos, empréstimos), isto é, uma variedade que funcionava como elemento do contato intercultural e comercial. É esta variedade que persiste até aos dias de hoje, mas não deve ser confundida como crioulização. Por enquanto, deixemos claro que

só aqueles indivíduos mais diretamente envolvidos com a máquina administrativa e com o meio coloquial (pequenos funcionários, intérpretes, ajudantes de balcão, serviços domésticos, etc.) eram obrigados a usar a língua portuguesa com mais frequência, e seu domínio poderia variar consoante o tempo de envolvimento com os colonos e/ou seu grau de escolaridade obtida, mesmo que o sistema rudimentar oferecido pela administração colonial (Zamparoni, 2009, p.45).

Para expandir a LP, o sistema colonial proibia através de leis e decretos o uso do landim ${ }^{2}$, quer dizer, as línguas bantu em instituições públicas, incluindo na escola. A igreja católica contribuiu fortemente para a implementação dessa política através da catequese. No entanto, a expansão do português começa a ter contornos inesperados pelo Governo Português - o surgimento de uma variedade do português de Moçambique. Os colonialistas portugueses perceberam na fala/ escrita formal esse desvio à norma, mas não puderam fazer muito porque eram poucos e também porque a ameaça anglófona circundava o território. Em outras palavras, o sistema colonial, mesmo vendo a dificuldade que os moçambicanos tinham em aprender o português, contentou-se com o pouco porque a ameaça inglesa era iminente. Lopes-Miguel (2004) explica que o

português e outras línguas europeias serviam para manter o domínio de uma pequena elite que, consequentemente, conduziu à subjugação e à retirada de poderes das sociedades africanas. É o grande e empobrecido campesinato, isto é, as largas massas do povo africano que são despojadas das suas condições socioculturais, econômicas, educacionais e linguísticas (Lopes-Miguel, 2004, p.477-478).

2. Empréstimo do inglês land-in. Foram os ingleses que deram o nome de land-in (landim) ao conjunto de línguas africanas faladas pelos africanos. 
Concluindo esse debate, temos a relembrar que a LP no tempo colonial era oficial e obrigatória e a sua história estava intimamente ligada à colonização, pois foi este processo que a trouxe e implantou nos princípios do século XV. Aliás, a Política Linguística do sistema colonial classificava todas as LB faladas em Moçambique como dialetos, fato que contraria a realidade dos moçambicanos e dos estudos linguísticos. Entendamos a política linguística como a "determinação das grandes decisões referentes às relações entre as línguas e a sociedade" e planejamento linguístico como "a sua implementação" (Calvet, 2007, p.11). O termo 'dialeto' está "carregado de preconceito racial e cultural, pois dialeto é uma forma errada, feia, ruim, pobre ou atrasada de se falar uma língua. Também é uma maneira de distinguir as línguas dos povos civilizados, brancos, das formas supostamente primitivas de falar dos povos selvagens." (Bagno, 2011, p. 380). Para Camacho,

todas as línguas e dialetos (variedades de uma língua) são igualmente complexas e eficientes para o exercício de todas as funções a que se destinam e nenhuma língua ou variedade dialetal é inerentemente inferior a outra similar a sua. Assim, dizer que uma variedade rural é simples demais e, portanto, primitiva, significa afirmar que há alguma outra variedade mais complexa e mais desenvolvida (Camacho, 2011, p.36).

As LB existentes em Moçambique (e não só) são línguas completas, com estrutura gramatical própria. Sobre este assunto, a linguista Alkmim (2001, p.41) explica que "toda a língua é adequada à comunidade que a utiliza, é um sistema completo que permite a um povo exprimir o mundo físico e simbólico em que vive." Antes da independência, líderes políticos engajados na luta pela independência adotaram o português como língua de comunicação entre os militares da Frente de Libertação de Moçambique. O objetivo foi de evitar conflitos étnicos, usando assim a "arma [língua] capturada ao inimigo que serviria para lutar contra esse inimigo, identificado como o colonialismo, o sistema colonial e não o povo português" (Silva, 2003, p. 30-39). Isso significa que a LP passou a ser instrumento de comunicação entre os militares durante a luta contra o colonialismo, uma vez que os militares eram provenientes de várias etnias e falavam várias LB.

\section{O português de Moçambique foi resultado de uma Transmissão Lin- guística Irregular?}

Tal como tentamos mostrar na primeira seção, a LP em Moçambique chegou por meio da colonização ocorrida nos séculos XV. A sua implementação encontrou uma resistência profunda por parte dos nativos devido à existência de uma diversidade linguística enorme em diferentes etnias e regiões espalhadas pelo 
extenso país $\left(801.590 \mathrm{~km}^{2}\right)$. As línguas faladas nesse período eram ágrafas, sem escrita, e a oralidade tinha maior prestígio no seio da população. A chegada dos primeiros exploradores gerou mudanças consideráveis na vida dos moçambicanos, sobretudo nas suas línguas nas grandes cidades.

Para que o sistema colonial ganhasse espaço, era necessário ensinar a LP aos moçambicanos, fato que não teve muito êxito porque os colonizadores não tinham interesse em ensinar, até porque não eram professores, nem acadêmicos na sua maioria, pois se assim fosse não teríamos apenas 1,2\% de moçambicanos que falavam português em 1980, quer dizer, 5 anos após a independência. Os colonos eram simplesmente militares, agricultores, pescadores e até prisioneiros. Hoje, o número de falantes do português como língua segunda aumentou para pouco mais de $10,7 \%$, mas as características se distanciam do português europeu. Por outro lado, as LB continuam firmes dentro e fora das cidades e nenhuma delas está em vias de extinção.

Para melhor percebermos o que aconteceu em Moçambique, precisamos trazer à tona os conceitos de Transmissão Linguística Irregular (TLI), de crioulo e de pidgin. Lucchesi e Baxter (2009) consideram TLI quando há uma situação de contato linguístico massivo, abrupto e radical, em que há uma redução da gama de funções desempenhadas pela comunicação verbal e uma perda de matéria gramatical que atinge estrutura abstrata. Esse aspecto não fez com que surgisse uma situação de pidginização e crioulização ${ }^{3}$ no contexto de Moçambique, tampouco no de Angola. Lucchesi e Baxter defendem que este processo resulta na "não aquisição/incorporação de morfologia e elementos gramaticais da língua de superstrato, que ocorre na fase inicial do processo [...] combinada com a reestruturação gramatical da nova variedade linguística" (Lucchesi e Baxter, 2009, p.121).

Há que realçar que esta transmissão "é um processo atestado em larga escala na história humana e costuma acontecer com qualquer movimento populacional ou de conquista significativa" (Naro e Scherre, 2007, p.140). Este processo originou o fanakaló (pidgin das minas da África do Sul), o afrikaans, o kabuverdianu (de Cabo Verde) e muitos outros crioulos de base portuguesa ${ }^{4}$, inglesa, francesa etc., espalhados pelo mundo. Vejamos o Mapa da localização de crioulos em África:

3. Surgiu em 1586-1590 para se referir a espanhóis nascidos nas Américas. No século XV, era um termo que designava os escravizados. Hoje a palavra crioulo designa um pidgin que possui falantes como língua materna. É uma língua que se forma em contextos sócio-históricos.

4. "Diz-se, então, que um crioulo é de base portuguesa quando as unidades lexicais são, na sua maioria, reconhecidamente de origem portuguesa, embora, na sua estrutura, sejam regidos por regras fonológicas e morfológicas próprias, possam ter significados diferentes e impliquem construções sintáticas também diferentes" (Pereira, 2006, p.47). 
Mapa 1: Localização dos crioulos em África

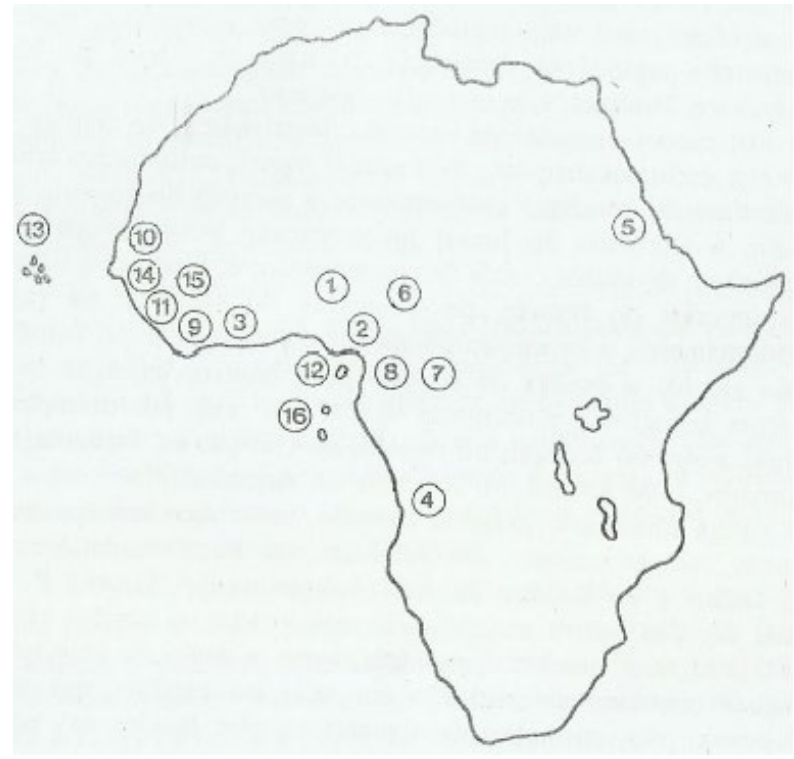

Legenda: 1.pidgin inglês da Nigéria; 2.pidgin inglês de Camarões; 3.pidgin inglês da Costa do Marfim;4. pretoguês de Angola; 5.pidgin italiano da Etiópia; 6.pidgin haussa da Nigéria; 7.Sango pidgin da República Centro Africana; 8. Ewondo pidgin de Camarões; 9.dyla pidgin da Costa de Marfim; 10. Cioulo inglês da Gâmbia; 11. Pidgin Sibéria; 12.crioulo ingles da ilhade Fernando; 13 crioulo português de Cabo Verde; 14.crioulo do Senegal; 15.crioulo da Guiné; 16.Crioulo português de São Tomé e Príncipe.

Fonte: Tarallo e Alkmim (1987, p.93)

Segundo Pereira (2006, p. 59), os crioulos de base portuguesa se dividem em dois grupos: "(a) crioulos de alta Guiné (Cabo Verde, Guiné-Bissau e Casamansa); (b) Golfo da Guiné (São Tomé e Príncipe e Ano Bom)". Vilela (1995) designa esses crioulos consolidados por crioulos primários.

Entendemos que a TLI nos leva a uma pidginização e/ou à uma crioulização, fato que não aconteceu em contexto sociolinguístico de Moçambique (e também de Angola), pois, vejamos: Lucchesi e Baxter (2009) explicam que a TLI se caracteriza pelo " recurso a um código emergencial de comunicação verbal"; necessidade de interação entre os senhores e capatazes e escravos. O Português de Moçambique surgiu de contextos semelhantes com as de TLI, mas teve um destino diferente. Por essa razão, não surgiram pidgins nem crioulos, quer dizer, os moçambicanos não precisaram de um código emergencial porque houve insistência no uso das LB. Não houve um contato direto entre os colonos e os escravos, porque havia capatazes (cipaios) que serviam de intermediários (intérpretes). Nesse caso, os capatazes eram moçambicanos e tinham a obrigação de 
aprender português por serem assimilados. Por outro lado, os escravizados só tinham que cumprir com as obrigações impostas sob tutela dos capatazes. As LB continuavam a ser utilizadas nas igrejas independentistas africanas e a LP "era quase uma ficção. Ninguém evangelizava nessa língua e nela quase não havia ensino [...] longe do que apregoava a lei, o que imperava pelo interior era a hegemonia cultural e linguística dos vários povos locais" (Zamparoni, 2009, p.39).

Em situações de TLI, as línguas nativas tenderiam a ser abandonadas, mas o que se verificou é uma resistência acirrada, de tal forma que, até 1980 (cinco anos após a independência), Moçambique só tinha 24,4\% de falantes de português, após 500 anos de colonização. Nesse sentido, o Português de Moçambique e o Português de Angola perderam/perdem a "matéria gramatical e lexical" da língua-alvo, caminhando de forma acelerada para uma nativização. Mas é importante sublinhar que em Moçambique e em Angola não se perdeu nada, pois não tinha ainda adquirido nada. Por isso as taxas de analfabetismos são elevadíssimas até hoje (Malik, 2013).

Segundo Naro e Scherre (2007, p.53), a TLI seria a "passagem de uma língua não-nativa a língua nativa de uma comunidade de fala", sem que tenha passado por uma pidginização nem crioulização. Trata-se de um processo novo na CPLP porque as características linguísticas de Angola e de Moçambique seguiram um destino histórico diferente, se compararmos com Cabo Verde, Guiné-Bissau e São Tomé e Príncipe. A situação de Moçambique colonial, portanto, não pode ser comparada com a situação do Brasil colonial, por que senão vejamos: (a) o Brasil recebeu, para além do colonizador, outros estrangeiros incluindo africanos; (b) a influência religiosa católica no Brasil foi mais forte do que em Moçambique; (c) o domínio do português foi mais forte do que as línguas nativas.

No Brasil, havia todas as condições para a implantação de um pidgin, mas o sistema colonial conseguiu controlar a situação. Há debates fortes sobre este aspecto no Brasil. Há autores que defendem a teoria segundo a qual o PB provém do pidgin e do crioulo de base portuguesa, mas há outros que não concordam plenamente.

Pereira (2006) esclarece que em Angola e em Moçambique não houve crioulos porque (a) as línguas africanas (maternas) eram usadas no cotidiano em todos os contextos, para lá das situações pontuais de comunicação com os portugueses; (b) havia muitos intermediários bilíngues como missionários e mercadores; (c) a extensão territorial é vasta, dado o número diminuto dos seus falantes (portugueses) em comparação com o número de falantes de LB; (d) a estabilidade e isolamento dos grupos rurais e a pouca mobilidade fortalecia as LB entre populações autóctones (Pereira, 2006, p.68). Segundo Zamparoni 
ao longo de séculos vimos desenrolar-se um processo, diríamos espontâneo e cotidiano, quer de moçambicanização da LP, quer de aportuguesamento das várias línguas locais. Não diria que a LP se adaptou ao meio. Diria que o meio adaptou às necessidades justamente porque não se pode perder de vista que esta não era uma troca entre iguais, na medida em que tais incorporações se davam em contexto em que a LP não representava nenhum poder conquistado e não contava com nenhuma estrutura efetiva e articulava para impor às demais línguas em presença; era uma pequena gota no oceano formado pelas múltiplas línguas locais (Zamparoni, 2009, p.30).

Concordamos com a tese de que o Português de Moçambique tenha tido algumas características da crioulização, mas que isso não chegou a se concretizar, tal como sustenta Vilela (1995). Adotamos o termo nativização, (termo também utilizado por Firmino, 2002; Vilela, 1995; Lopes-Miguel, 2004) para designar o processo de transformação da norma-padrão europeia em PM, uma variedade que, tendo como na base as LB, adapta, integra na língua seus valores culturais, sua identidade, seus símbolos, seus objetos materiais, de tal forma que seja sentida como pertence dos moçambicanos. A nativização da LP em Moçambique aumenta à medida que os falantes da LP aumentam, incentivados pelo prestígio social e político, por ser língua nacional e internacional. Consideramos uma TLI um estágio mais profundo amparado pelos contextos sócio-históricos mais complexos.

Fechamos este debate respondendo a pergunta inicial: em Moçambique, houve uma nativização do português fruto de aprendizagem irregular por parte de poucos moçambicanos. Conforme vimos em Zamparoni (2009), os moçambicanos jamais falaram a norma-padrão europeia. Os poucos escolarizados começaram a simplificar algumas regras, influenciados, de certa forma, pelas LBm criando assim a variedade moçambicana. O processo de nativização ou moçambicanização pode ter se iniciado mesmo antes do envio dos primeiros escravizados para a Europa e para as Américas. Sabemos que não existe uma língua simples. Todas as línguas têm a sua complexidade, mas Vilela (1995) confere a simplicidade com a relação aos fenômenos de integração de características gramaticais das diversas $\mathrm{LBm}$. É simples para quem recria e incorpora na língua por ter como referência a sua língua materna, uma LBm. É que o português angolano ou moçambicano apresenta indícios claros de afirmação da norma própria, principalmente a "força do léxico do português a adaptar-se à mentalidade africana, tanto nos semas inerentes como nos semas classemáticos" (Vilela, 1995, p.68).

\section{O português de Moçambique e os moçambicanismos}

Devido às variáveis sociais, o português falado em Moçambique se distancia do português europeu, brasileiro, angolano, guineense etc. Segundo Lopes, Sitoe e Nhamuende (2013, p.17) “em Moçambique vem-se desenvolvendo uma varieda- 
de de português que é moçambicana, no sentido em que há traços, características e realizações formais e contextuais de moçambicanidade na fala e na escrita..." Os Moçambicanismos seriam

indícios claros de afirmação de norma própria: na maneira original como adota o seu vocabulário de
origem bantu ao sistema português divergindo inclusivamente da norma europeia (lusitana), no modo
como simplifica a morfologia flexional do português, como começa a optar pela ordenação dos ele-
mentos frásicos na sequência discursiva e, sobretudo, como força o léxico do português a adaptar-se à
mentalidade africana, tanto nos semas inerentes como semas classemáticos: o que implica, por vezes,
uma reformulação do esquema frásico em alguns dos seus modelos proposicionais (Vilela, 1995, p.68).

Nessa variedade, o que salta mais à vista dos falantes é a variação lexical, fonética e semântica. Até nos dias de hoje, os falantes da língua xichangana ainda dizem: ku dlaya nyocana! (matar o bicho!) para se referir à primeira refeição do dia que ocorre antes das $12 \mathrm{~h}$. E, assim, houve transporte desse contexto para português: "mata-bicho" que significa "café da manhã" (no português do Brasil) ou pequeno-almoço (no PE). As palavras e expressões sograria (casa dos sogros), cortar o ano (réveillon), falar-alto (subornar/corromper), wasso-wasso (feitiçaria para amar alguém), tchapo-tchapo (rápido), pasta (mochila), machamba (horta, roça), madala (idoso), baraca (lanchonete) ocorrem no PM e estão intimamente ligados à cultura moçambicana.

É frequente percebermos, em comunicação cotidiana, as transformações e a integração de várias palavras provenientes das LBm. Por exemplo, timbila/timbilas (xilofone/xilofones), pala-pala/pala-palas (chifre/chifres de antílope), capulana/capulanas (tecido de algodão que as mulheres usam como adorno amarrado à volta da cintura), tchova/ tchovas (carrinho / carrinhos de mão), madala/ madalas (idoso / idosos), mamana / mamanas (mãe/mães), molwene / molwenes (marginal / marginais), mufana / mufanas (rapaz / rapazes). É interessante deixar claro que a palavra timbilas aportuguesou-se com adaptação de marcação de número de duas línguas: -mbila (singular) e 'ti' (prefixo do plural). Quando se adiciona 's' está se adicionando mais uma marca gramatical na mesma palavra. Portanto, ti (marca do plural das línguas do grupo tsonga) e s (para o plural em português).

Os exemplos de 1 a 10 foram extraídos de Gonçalves (2013). Nesse artigo, a autora discute os erros do português de Moçambique quando equiparados à norma-padrão europeia (Português Europeu/PE) exigida pelas gramáticas tradicionais em uso em Moçambique. Segundo Gonçalves (2013, p.6-11), no português de Moçambique, há interferências sintáticas provenientes das línguas bantu moçambicanas:

(1) O meu irmão foi concedido uma bolsa de estudos. (sem equivalente no PE) 
(2) Tu também podes nascer um filho saudável. ( $\mathrm{PE}=$ dar a luz)

(3) $\mathrm{O}$ presidente afirmou que não sei. ( $\mathrm{PE}=$ afirmou que não sabia)

(4) Ele saiu em casa muito cedo. ( $\mathrm{PE}=\mathrm{de}$ casa)

No português de Moçambique, constata-se a ausência de concordância verbal e nominal em frases. Os exemplos (5) e (6) ilustram esse fenômeno da variação com relação ao Português Europeu (PE):

(5) Muitos já não respeita a tradição. ( $\mathrm{PE}=$ respeitam)

(6) Rituais religioso só conheço um. ( $\mathrm{PE}=$ religiosos)

Para além da falta de concordância verbal e nominal, nota-se que há flexão indevida do infinitivo. Assim, vejamos os exemplos (7) e (8):

(7) Os alunos propuseram fazerem o trabalho em dois dias. ( $\mathrm{PE}=$ fazer)

(8) Os chefes deviam criarem melhores condições para todos ( $\mathrm{PE}=$ criar)

No Português de Moçambique, é frequente ocorrer a neutralização de formas próprias para o tratamento por tu/você. Para ilustrar, vejamos os exemplos (9) e (10).

(9) Jovem universitário, procure o teu lugar. ( $\mathrm{PE}=$ procure.../...seu)

(10) Você não tinha nada que falar, porque ele não é teu irmão. ( $\mathrm{PE}=\mathrm{seu}$ )

Sob ponto de vista fonético-fonológico, Ngunga (2012, p.10) apresenta a inserção da nasal, tal se pode ver nos seguintes exemplos: convinte* / 'convite', enkonomiya* / 'economia', enzagero* / 'exagero', enzame* / 'exame', enzixte* /'existe', etc. Há ainda a o desvozeamento dos sons consonânticos para falantes do emakhuwa como língua materna: kasa*/“caça', kasa*/“casa’, kasa*/‘Gaza's, teto*/ 'dedo'. (Ngunga, 2012, p.11).

\section{A comunidade linguística e o material de análise}

O presente estudo é fruto de uma pesquisa de campo realizada com falantes do português como segunda língua nas províncias de Maputo e Nampula, em 2012. A escolha dessas duas cidades se justifica pelo fato de que são as mais populosas de Moçambique e onde se concentram populações provenientes das diferentes províncias de Moçambique. É importante referir que foram entrevistados 36 informantes, sendo 16 em Maputo e 20 na cidade de Nampula. As gravações foram realizadas por um gravador GPx Digital Voice Recorder 701, com "consentimento livre e esclarecido" dos falantes. As gravações foram codificadas por forma a preservar a identidade dos falantes, totalizaram 3 horas e 11 minutos e foram armazenadas em formato Windowns mídia áudio. Em seguida, foram transcritas utilizando "Normas para transcrição" de Favero, Andrade e Aquino (2000, p.118-

5. Gaza é uma das dez províncias de Moçambique. Localiza-se na região sul de Moçambique, bem ao lado da província de Inhambane. 
119). É importante referir que a língua materna dos falantes de Nampula é a emakhuwa e os de Maputo é a xichangana.

As variáveis sociais tidas em conta nesta pesquisa são: cidade (Nampula/Maputo), escolaridade (primário/secundário/superior), classe social (baixa, média/ alta), língua de origem do dado (bantu/inglês/árabe/outro), local (zona urbana e suburbana), item lexical dicionarizado (sim/não) classificação do dado (nome/ verbo/expressão). A variável linguística estudada é a variação lexical por meio de estrangeirismos. Após a transcrição das gravações, os dados foram analisados pelo GoldVarb 2001 e se obteve a seguinte tabela de resultados:

Tabela 1: Dados principais

\begin{tabular}{|c|c|}
\hline & Estrangeirismos \\
\hline Input & 0,84 \\
\hline Significância & 0,03 \\
\hline Logaritmo de significância & $-83,033$ \\
\hline Total dos dados & 267 \\
\hline
\end{tabular}

Fonte: Timbane (2013b)

Observando a tabela 1, nota-se que o input da "melhor rodada" é muito significativo, ou seja, há uma probabilidade grande de ocorrência de estrangeirismos na fala dos moçambicanos entrevistados. Os estrangeirismos aparecem na fala por causa de interferências vindas das LB e/ou pelo fraco conhecimento do português por ser segunda língua. Contrariamente ao estrangeirismo, o empréstimo exige que o falante domine, ou pelo menos conheça, as regras da língua receptora para que estas sejam aplicadas. Em Nampula, há uma defasagem maior entre estrangeirismos e empréstimos, quer dizer, os nampulenses incorporam mais estrangeirismos (88\%) do que os empréstimos. Em Maputo, a diferença entre estrangeirismos e empréstimos é de $17,4 \%$, fato que nos leva a crer que há uma diferença relativamente menor entre os dois fenômenos.

Além disso, os resultados da pesquisa mostram que não há diferença do uso de estrangeirismos entre a zona urbana $(75,9 \%)$ e suburbana $(76,2 \%)$. Este dado mostra o entrosamento entre pessoas residentes na zona urbana e suburbana. Isso se justifica pelo fato de que as pessoas da zona urbana e suburbana conviverem de forma harmoniosa nos dois ambientes separados pela divisão administrativa. Os limites geopolíticos são diferentes dos limites linguísticos, portanto, esses limites nunca impedem a interação entre os falantes da mesma língua ou variante. Esta transposição dos limites geopolíticos acontece com os empréstimos/ estrangeirismos. Com relação ao grau de escolaridade, os informantes com nível escolar 
primário são os que mais incorporam estrangeirismos na fala $(\mathrm{PR}=0,88)$. Curiosamente, o grupo que integra os estrangeirismos integrando-os na gramática do português é o grupo com nível de escolaridade superior $(\mathrm{PR}=0,90)$. Esperávamos que fossem os menos escolarizados a praticar este fenômeno pelo fato de não ter conhecimento suficiente da LP.

No que se refere ao sexo/gênero dos informantes, os resultados da pesquisa mostram ainda que os estrangeirismos nos homens ocorreram em 79,8\% e em mulheres $70,2 \%$ - uma diferença não muito acentuada de 9,6\%, referente aos empréstimos. Os dados do gênero fizeram mais sentido ao cruzarmos com outras variáveis. O mesmo fenômeno não se verificou com a variável independente idade. Segundo Malik (2013), a taxa de alfabetismo dos adultos (5 ou mais anos) é de $56,1 \%$. A pré-hipótese é a de que quanto menor for o conhecimento de uma língua, maior é a ocorrência de estrangeirismos e empréstimos. Sendo assim, tanto os adultos quanto os idosos produzem estrangeirismos em $76,7 \%$ e $75,7 \%$, respectivamente, dados que mostram a igualdade pelo menos neste fator. Os adultos (talvez pelo baixo nível de escolaridade) produziram $66,3 \%$ de estrangeirismos e os adultos escolarizados $33,7 \%$. Estes resultados mostram que o grau de escolaridade influencia na redução da ocorrência dos estrangeirismos, porque o falante escolarizado procura alternativas lexicais logo que encontra algum impasse ou obstáculo na comunicação.

Os entrevistados com escolaridade primária e secundária apresentaram mais estrangeirismos comparativamente aos do ensino superior. Este dado parece pouco significativo porque, num universo de 36 falantes, conseguimos entrevistar quatro pessoas com nível superior, todas da cidade de Maputo. Se formos analisar a percentagem dos falantes de ensino superior, eles representam $11,1 \%$ do total. Os empréstimos são mais produzidos por falantes de ensino secundário, talvez porque já dominem as regras gramaticais da LP. Os estrangeirismos passam a seguir as normas da língua de chegada na maior parte dos casos. Se é substantivo na língua de origem continua sendo como tal na língua de chegada. O verbo lobolar (ato de realizar dote) provém do verbo ku lovòlà (dar dote) na língua xichangana, por exemplo.

Há integração deste verbo em português, que passa a ser verbo da primeira conjugação (termina em -ar). Se tivéssemos entrevistado um número mais representativo de falantes de ensino superior, teríamos provavelmente outras tendências percentuais. O nível social tem influenciado no domínio ou não da LP. Pessoas com nível social alto têm mais oportunidades de apreender, estar em contato com mídias do tipo televisão, jornal, rádio, internet e podem, de certa forma, adquirir mais conhecimentos da língua. Muitas pessoas com nível social 
alto vivem nas zonas urbanas rodeadas de oportunidades.

Sendo assim, os dados da pesquisa ilustram que falantes pertencentes à classe social média apresentam mais estrangeirismos do que os da classe baixa. Contrariamente aos estrangeirismos, os empréstimos ocorrem mais em falantes de nível social baixo (30,8\%). Dos 267 dados das entrevistas, constatamos que 93,3\% são nomes ou substantivos e que $78 \%$ dos substantivos são estrangeirismos. Vejamos alguns exemplos extraídos do corpus. Entre parêntesis, está indicado o código do informante (inf.) ${ }^{6}$ :

(11) “... leva aquela caracata põe na panela no fogo diminui água...” (inf. B18).

(12) "...vou ser fã de kuduro, quer dizer cada pessoa nasce e tem maneira..." (inf. B15).

(13) “...aqui é catchiza, sim esta aqui abúxta, esta aqui adhuwace..." (inf. B4).

(14) “...é a dança de errenqueia de Mwecape...sim senhor...”(inf. B3).

(15) "...uma mulher deve vestir, o que uma capulana ou outros vestidos..." (inf. A8).

(16) "...o cantor Ziqo a pandza que ele faz, ele tem uma mensagem sim..." (inf. A7).

(17) "...a cantora, ela canta a marrabenta e a música dela tem mensagem..." (inf. A4).

Os substantivos em itálico ocorrem em PM e resultam das diversas LBm faladas em diferentes comunidades linguísticas. Ao cruzar-se o local de residência e a língua de origem do fenômeno, não percebemos nenhum caso de estrangeirismo proveniente da língua árabe na cidade de Maputo, enquanto que em Nampula obtivemos $87 \%$, dado que comprova a influência da cultura árabe no norte do país. Os estrangeirismos do inglês ocorrem com maior frequência tanto em Maputo quanto em Nampula, comparativamente às outras línguas. A província de Nampula não faz fronteira com nenhum país anglófono, mas a ocorrência foi considerável devido ao impacto do inglês ao nível internacional. Os estrangeirismos provenientes das línguas bantu foram observados em 94\% na cidade de Nampula, dado sustentado pelos índices baixos de alfabetismo.

Tabela 2: Cruzamento entre local de residência e a língua de origem de fenômeno

\begin{tabular}{|l|l|l|}
\hline & MAPUTO & NAMPULA \\
\hline
\end{tabular}

6. Significado dos substantivos em português: (11) tipo de peixe; (12) tipo de dança angolana; $(13,14)$ tipos de instrumentos musicais; (15) tecido que as mulheres amarram na cintura e que serve para embalar a criança ou fazer roupas; $(16,17)$ tipo de dança. 


\begin{tabular}{|c|c|c|}
\hline BANTU & $45 / 120=60 \%$ & $75 / 120=94 \%$ \\
\hline OUTRAS & $2 / 6=13 \%$ & $4 / 6=40 \%$ \\
\hline INGLÊS & $17 / 31=89 \%$ & $14 / 31=93 \%$ \\
\hline ÁRABE & $0 / 46=0 \%$ & $46 / 46=87 \%$ \\
\hline TOTAL & $64 / 203=59 \%$ & $139 / 203=88 \%$ \\
\hline
\end{tabular}

Fonte: Timbane (2013b)

Esses dados reforçam a tese de que os estrangeirismos vêm completar lacunas, quer dizer a falta de unidades lexicais correspondentes para determinados fenômenos. Cerca de $88,9 \%$ dos verbos encontrados nos corpora são empréstimos que obrigatoriamente seguem as regras do português, passando a pertencer à $1^{\mathrm{a}}$ conjugação, como vemos em:

(18) “...como estão a lobolar tinha que fazer dois: um para o pai, um para..." (inf. A1).

O mesmo se pode dizer dos verbos nholar, chuapar que vêm de $k u$ nhola (estar em posição de servir os outros num jogo de bolinha, jogo de garrafinha ou de linha) e ku chuapa (roubar). As expressões que correspondem a estrangeirismos são frequentes no português e muitas delas provêm do árabe. Tomemos alguns exemplos. Entre parênteses o código e o significado:

(19) “...e acontece que no dia de kiyamah...” (inf. B1). (Trad. 'ressurreição, fim do mundo')

(20) “...profeta suallalahu alaihi wa sallama...” (inf. B1). (Trad. 'Profeta que faz com que a paz e bênção de Deus estejam com ele')

(21) “...subhanahu wa ta'ala...” (inf. B1) (Trad. 'Glória a Deus o Altíssimo')

As expressões e as palavras provenientes do árabe correspondem a 86,8\% (46/53) e todas ocorrem na província de Nampula. Curiosamente, a província de Maputo não apresentou nenhum caso de palavra ou expressão árabe. Esse dado nos leva a concluir que os estrangeirismos do árabe são manifestações linguísticas que ocorrem exclusivamente no norte de Moçambique onde a religião muçulmana é mais frequente.

Os estrangeirismos no português de Moçambique não estão dicionarizados $(89,6 \%)$, embora sejam frequentes e utilizados na comunicação do dia a dia. Entendemos isso pelo fato de que Moçambique ainda não tem um dicionário próprio formalmente autorizado para ser usado nas escolas. É válido destacar que, no país, já há dois dicionários impressos: a) um Minidicionário de Moçambicanismos de Hildizina Dias publicado em 2002) e b) Moçambicanismos: para um léxico de usos do português moçambicano de Armando J. Lopes, Salvador J. Sitoe e Paulino J. Nhamuende (2013). Na análise, os dois livros se complementam entre si, porque 
unidades lexicais que tem num, não existem noutro. Isso significa que precisamos trabalhar para construir um dicionário que reflete de forma íntegra a riqueza lexical presente no contexto moçambicano.

\section{Conclusão}

Como pudemos constatar nesta pesquisa, o Português de Moçambique se distancia do Português Europeu, sobretudo em nível lexical, fonológico e semântico. Este é um rumo percorrido por qualquer língua viva, pois se assim não fosse estaríamos falando latim. As entradas de termos vindos das diversas LB se justificam pelo fato de que os contextos socioculturais moçambicanos interferem na comunicação e forçam a marcação da identidade. É através dos moçambicanismos que conseguimos identificar de onde é uma determinada variedade. Em nenhum outro país da CPLP se diz txopela para 'motocicleta', txova para 'carinho de mão', dumba-nengue para 'mercado informal', molwene para 'menino sem teto e desamparado', lobolar para se referir ao 'ato de entregar dote', my love para se referir ao 'caminhão que serve de meio de transporte de pessoas', matapa para tipo de 'prato feito na base de folhas da mandioqueira', e por aí em diante. São unidades lexicais que ocorrem em contexto sociolinguístico moçambicano e particularizam a variação lexical. Muitas dessas novas entradas lexicais (neologismos) são necessárias, o que significa que não existe seu equivalente em PE ou PB.

O PM é uma realidade eminente e o importante é continuarmos a pesquisar e a descrever esta variedade por forma a melhor lidarmos com o ensino do português nas escolas moçambicanas. É importante sublinhar que a língua portuguesa ainda é obstáculo no progresso da educação moçambicana. Por isso, algumas vozes defendem uma educação bilíngue a fim de se ultrapassar tais dificuldades.

Voltando para o PM, é importante mostrar que cada linguista precisa dar seu contributo para que a variedade seja reconhecida pelas autoridades que gerem a política e o planejamento linguístico. Cremos que não se pode bloquear o progresso normal da língua. Essa tentativa frustrou-se no Brasil com o Projeto de Lei 1676/99 (Brasil, 1999) que tramitou, mas que não teve desfecho positivo. Estávamos todos ansiosos em ver o primeiro a ser condenado pela justiça pelo fato de ter usado um estrangeirismo na sua fala. Seria algo inédito, pois o próprio português do Brasil é formado por muitas palavras estrangeiras advindas das mais de 170 línguas indígenas (Rodrigues, 2010). Analisando bem, os estrangeirismos não têm nada a ver com território político-administrativo, mas sim ao à língua.

Vimos que o PM surgiu com a colonização. Devido à distância geográfica com Portugal, o português tomou outros rumos em função do multilinguismo e do mul- 
ticulturalismo que contribuíram de forma significativa nos níveis lexical, semântico, morfossintático, fonético-fonológico. Hoje o português é uma língua nacional e é, de fato, uma língua moçambicana de origem europeia, com falantes nativos e responde prontamente às necessidades comunicativas dos moçambicanos.

A variedade do português de Moçambique é uma realidade e deve ser estudada sem preconceito. Sabendo que as línguas mudam, é normal que o português de Moçambique tenha características diferentes das do português europeu, brasileiro, são tomense ou angolano. É que cada contexto sociocultural possui características próprias que moldam o comportamento linguístico. Existe um conjunto de características que permitem a comunicação na lusofonia - que é o sistema. É no sistema em que ficam armazenadas as regras gerais das línguas (Coseriu, 1962; 1989). Portanto, continuaremos falando a língua portuguesa e usufruindo das regras do seu sistema. Mas a norma irá variar segundo os usos práticos que se iniciam na individualidade. A fonologia, o léxico e a semântica jamais serão iguais como os de "Lisboa", mesmo havendo vontade política nesse sentido.

Estamos conformados com a realidade de que a lusofonia é um espaço plurilíngue e multicultural. Sendo assim, a língua portuguesa continuará variando e mudando ao longo dos tempos resultado da necessidade comunicativa dos seus falantes. As palavras txopela (moto-taxi), lobolo (dote), djimar (fazer ginástica), matapa (prato feito com folhas de mandioca), mahala (gratuito), e muitas outras, ocorrem/ocorrerão no contexto de Moçambique, daí que designamos por moçambicanismos. O importante seria que cada lusófono criasse seu próprio dicionário e gramática que responda à realidade local. Os professores "sentem na pele" a dificuldade que os alunos moçambicanos enfrentam quando consultam um dicionário de outra variedade. Os escritores moçambicanos não se distanciam desta variedade daí a dificuldade quando se usa dicionário de outra variedade. Todos os mídia que circulam em Moçambique dificilmente contornam esta realidade sociolinguística local, o que significa que traços da variedade estão presentes no cotidiano. Seria interessante reconhecer a variedade do português de Moçambique, consolidá-la e criar condições pedagógicas para que seja discutida em sala de aula sem preconceito, demonstrando que as variações linguísticas são fenômenos naturais em todas as línguas vivas.

\section{Referências}

Alkmim, Tânia M. Sociolinguística. In: Mussalim, Fernanda; Bentes, Anna Cristina. (Org.). Introdução à linguística: domínios e fronteiras. v.1. São Paulo: Cortez, 2001. p. 21-48.

Brasil. Projeto de Lei 1676/99. Lei dos estrangeirismos. Disponível em: <http://www.camara. gov.br/sileg/integras/153443.pdf>. Acesso em: 11 mai.2017. 
Bagno, Marcos. O que é uma língua? Imaginário, ciência e hipótese. In: Lagares, Xoan C.; Bagno, Marcos. (Org.). Políticas da norma e conflitos linguístico. São Paulo: Parábola, 2011. p. 355-388.

Calvet, Louis-Jean. As políticas linguísticas. São Paulo: Parábola, 2007.

Camacho, Roberto. Norma culta e variedades linguísticas. Caderno de formação: formação de professores didática geral. v.11. São Paulo: Cultura Acadêmica, 2011. p.34-49.

Cintra, Luís F. Lindley. "Nova proposta de classificação dos dialectos galego - portugueses" in: Boletim de Filologia, Lisboa, Centro de Estudos Filológicos, v.22, 1971, p. 81-116. Disponível em: $<$ http://cvc.instituto-camoes.pt/hlp/biblioteca/novaproposta.pdf>. Acesso em: 22 jun.2017.

Coseriu, Eugenio. "Sistema, norma y habla”. Teoría del lenguaje y lingüística general, Madrid: Gredos, 1962.

Coseriu, Eugenio. Teoría del lenguaje y linguística general: cinco estuios. 3.ed. Madrid: Gredos, 1989. Disponível em: <https://bondideapuntes.files.wordpress.com/2017/04/coseriu-eugenio-sistema-norma-y-habla.pdf $>$. Acesso em: 22 jun. 2017.

Favero, Leonor Lopes; Andrade, Maria Lúcia da Cunha V. Oliveira; Aquino, Zilda Gaspar Oliveira. Oralidade e escrita: perspectivas para o ensino de língua materna. São Paulo: Cortez, 2000.

Firmino, Gregório. A questão linguística na África pós-colonial: o caso do português e das línguas autóctones em Moçambique. Maputo: Promédia, 2002.

Gonçalves, Perpétua. Afinal o que são erros de português. Primeiras Jornadas de Língua Portuguesa: dinâmicas do português de Moçambique. Maputo, 26 de maio. Disponível em: $<$ http://www. catedraportugues.uem.mz/lib/docs/Jornadas\%202013\%20(2005).pdf>. Acesso em: 28 mai. 2014.

Guthrie, Malcolm. The classification of the bantu languages. London: OUP, 1948.

Haugen, E. Dialeto, língua, nação. In: Bagno, Marcos. (Org.) Norma linguística. São Paulo: Layola, 2001.p.97-114.

Heine, Bernd; Nurse, Derek. African languages: an introduction. Cambridge: CUP, 2000.

Malik, Khalid. Relatório de desenvolvimento humano. New York: PNUD, 2013.

Moshi, Lioba. The Globalized World Languages: the case of Kiswahili. Selected Proceedings of the 36th Annual Conference on African Linguistics. Arasanyin, Olaoba F. ; Pemberton, Michael A. (Eds.). Somerville, MA: Cascadilla Proceedings Project. p.166-175, 2006.

Lopes-Miguel, José de Sousa Miguel. Cultura acústica e letramento em Moçambique em busca de fundamentos antropológicos para uma educação intercultural. São Paulo: EDUC, 2004.

Lopes, Armando Jorge; Sitoe, Salvador J.; Nhamuende, Paulino J. Moçambicanismos: para um léxico de usos do português moçambicano. Luanda: Editora Letras, 2013.

Luchchesi, Dante; Baxter, Alain. A transmissão linguística irregular. In: Lucchesi, Dante; Baxter, Alain; Ribeiro, Ilza. (Org.). O português afro-brasileiro. Salvador: EDUFBA, 2009. p.101-124.

Naro, António J; Scherre, Maria Marta P. Origens do português brasileiro. São Paulo: Parábola, 2007.

Ngunga, Armindo. Interferências de línguas moçambicanas em português falado em Moçambique. Revista Cientifica da Universidade Eduardo Mondlane. v.1, $\mathrm{n}^{\mathrm{o}}$ 0, 2012. p.7-20. 
Ngunga, Armindo. Dicionário da língua de sinais. Maputo: CEA, 2013.

Ngunga, Armindo; Faquir, Osvaldo G. Padronização da ortografia de línguas moçambicanas: Relatório do III Seminário. Col. As nossas línguas. Maputo: CEA, 2011.

Pereira, Dulce. O essencial sobre a língua portuguesa: crioulos de base portuguesa. Lisboa: Caminho, 2006.

Rodrigues, Ayron. Tupi, tupinambá, línguas gerais e português do Brasil. In: Noll, Volker; Dietrich, Wolf. (Org.). Português e o tupi no Brasil. São Paulo: Brasil, 2010. p.27-48.

Silva, C. Ensino monolíngue e o insucesso escolar em Moçambique: escolarização bilíngue melhorará também o ensino de português. Aprender juntos. Maputo: CELP, 2003, s.p.

Tarallo, Fernando.; Alkmim, Tânia. Falares crioulos: línguas em contato. São Paulo: Atica, 1987.

Timbane, Alexandre António. A variação linguística e o ensino do português em Moçambique. Confluências. ${ }^{\circ} 43,2^{\circ}$ sem. Rio de Janeiro, p.263-286, 2013a.

Timbane, Alexandre António. A variação e a mudança lexical de lingua portuguesa em Moçambique. (Tese de doutorado). Faculdade de Ciências e letras, Universidade Estadual Paulista Júlio de Mesquita Filho, Araraquara, 2013b.

Timbane, Alexandre António. O ensino da língua portuguesa em Moçambique e a problemática da formação de professores primários. Artificios. v.4, n.7, p.1-21, jun 2014. Disponível em: <http:// www.artificios.ufpa.br/Artigos/Revista7/Texto\%20Alexandre.pdf $>$. Acesso em 22 jun. 2017.

Vilela, Mário. Ensino da língua portuguesa: léxico, dicionário, gramática. Coimbra: Almeida, 1995.

Zamparoni, Valdemir D. Entre narros e mulungos: colonialismo e paisagem social em Lourenço Marques c.1890-c.1940. Tese (doutorado) - Faculdade de Filosofia, Letras e Ciências Humanas, Universidade de São Paulo. São Paulo, 1998.

Zamparoni, Valdemir D. As escravas perpétuas e o ensino prático: raça, gênero e educação no Moçambique colonial, 1910-1930. Revista Estudos afro-asiáticos. v.24, n³. 2002. p.459-482.

Zamparoni, Valdemir D. Colonialismo, jornalismo, militância e apropriação da língua portuguesa em Moçambique nas décadas iniciais do século XX. In: Galves, Charlotte.; Garmes, Hélder; Ribeiro, Fernando Rosa. (Org.). África-Brasil: caminhos da língua portuguesa. Campinas-SP: Unicamp, 2009. p. 27-58. 